story. Compliance with research standards, including data-sharing, should be supported, audited and acknowledged.

Records and quality management. Laboratory notebooks and records must be available for independent review. Electronic laboratory notebooks facilitate collaboration, supervision and record keeping, and can link records to the original data. One of our institutions (U.D.s) is now adopting these system-wide. Random audits should be conducted to guarantee that experimental data are duly recorded and that elements of good research practice are routine. Such spot-checks are commonplace in industry.

Appropriate incentive and evaluation systems. Institutions should find ways to deter non-compliance with guidelines, poor mentoring and scientific sloppiness. Faculty members with poor records should face loss of laboratory space and trainees, decreased funding and potential demotion. Conversely, faculty members who excel as mentors and careful experimentalists should be rewarded. Appropriate metrics should be developed so that promotions are based on robustness and high-quality mentoring, rather than simply on high-profile publications ${ }^{6}$. Surveys such as that conducted at MD Anderson exemplify one way in which administrators can gain the insight necessary to improve the research environment. Institution-level metrics could help to monitor overall performance and remind all researchers and administrators of their responsibility to the scientific community.
Enforcement. Institutions should investigate egregious lapses and record them in a routine, transparent way. Departments of research integrity or other centres of excellence should be funded, staffed and given enough authority to prevent, detect, investigate and penalize poor-quality research. They should also be charged with promoting an institutional culture that nurtures robustness.

\section{GETTING TO GIP}

The systems needed to promote reproducible research must come from institutions scientists, funders and journals cannot build them on their own. These kinds of changes will require additional money, infrastructure, personnel and paperwork. The load on institutions and investigators will be real, but so is the burden of irreproducible research. Even if it is accompanied by an apparent decrease in productivity, the resulting increase in research quality will be well worth the costs.

Still, most institutions will not make the necessary moves unless forced. Funding bodies should make GIP a prerequisite for receiving a grant. The concept has gained some traction: last year, Science Foundation Ireland announced plans to conduct external audits on some of the labs that it supports.

There will not be one ideal solution. Faculty members, trainees and administrators will need to come together for honest, difficult discussions to restructure institutions. Neither scientists nor institutions should engage in mere box checking; new practices must restrain sloppiness while interfering only minimally with the many scientists who are behaving well.
Large-scale change is possible. In the 1970s, clinical research had little rigour or oversight. Now clinical trials routinely include concurrent control groups, doubleblinding, pre-specified endpoints, power calculations to determine patient numbers and analysis plans that thwart bias. In addition, primary data are available for independent statistical analysis by regulatory authorities. At the time, these changes were controversial; many physicians believed them to be unnecessary and regressive.

Nothing an institution can do will prevent misconduct altogether. This is not the goal. Rather, it is to support the work of wellmeaning scientists, to reduce the waste from biased results, and to relieve some of the pressures that encourage sloppy science. .

C. Glenn Begley is chief scientific officer at TetraLogic Pharmaceuticals, Malvern, Pennsylvania, USA. Alastair M. Buchan is dean of medicine and head of the Medical Science Division, Oxford NIHR Biomedical Research Centre, University of Oxford, UK. Ulrich Dirnagl is director of the Center for Stroke Research at the Universitätsmedizin Charité Berlin, Germany.

e-mail:cgbegley@tlog.com

1. Begley, C. G. \& Ellis, L. M. Nature 483, 531-533 (2012).

2. Prinz, F., Schlange, T. \& Asadullah, K. Nature Rev. Drug Discov. 10, 712-713 (2011).

3. Collins, F. S. \& Tabak, L. A. Nature $\mathbf{5 0 5 , 6 1 2 - 6 1 3}$ (2014).

4. Begley, C. G. Nature 497, 433-434 (2013).

5. Mobley, A., Linder, S. K., Braeuer, R., Ellis, L. M. \& Zwelling, L. PLOS ONE 8, e63221 (2013).

6. Ioannidis, J. P. \& Khoury, M. J. J. Am. Med. Assoc. 312 , 483-484 (2014)

\title{
Push renewables to spur carbon pricing
}

\section{Make wind and solar power even cheaper by opening up access to the electricity grid and ending fossil-fuel subsidies, urge Gernot Wagner and colleagues.}

$\mathrm{P}$ utting a price on carbon dioxide and other greenhouse gases to curb emissions must be the centrepiece of any comprehensive climate-change policy. We know it works: pricing carbon creates broad incentives to cut emissions. Yet the current price of carbon remains much too low relative to the hidden environmental, health and societal costs of burning a tonne of coal or a barrel of oil ${ }^{1}$. The global average price is below zero, once half a trillion dollars of fossil-fuel subsidies are factored in.
Momentum towards effective carbon pricing is building. California, joined by the Canadian province of Quebec, leads by pricing $85 \%$ of such emissions at around US $\$ 12$ per tonne. Sweden applies the highest value globally on half of its carbon dioxide emissions, at up to $\$ 125$ per tonne. The European Union has the largest system in terms of tonnes covered, pricing $45 \%$ of its greenhouse-gas emissions at about $\$ 8$ per tonne. China is experimenting with regional cap-and-trade systems. And the US Clean Power Plan encourages states to meet emissions-reduction targets through market-based mechanisms. Yet global emissions continue to climb.

The current inadequacy of carbon pricing stems from a catch-22. Policymakers are more likely to price carbon appropriately if it is cheaper to move onto a low-carbon path. But reducing the cost of renewable energies requires investment, and thus a carbon price.

In our view, the best hope of ending this logjam rests with tuning policies to drive down the cost of renewable power 


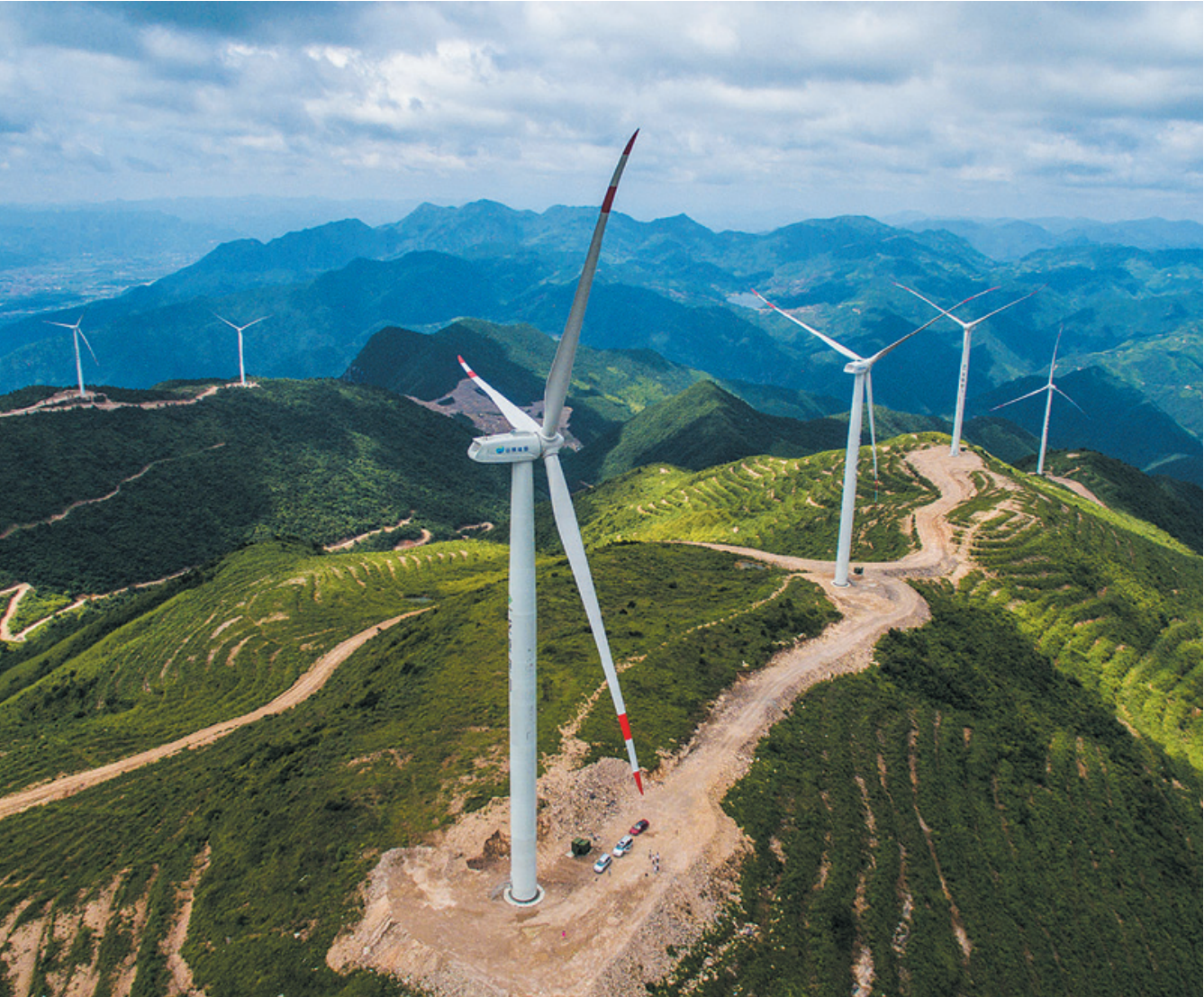

China (left) has invested in renewables supply, whereas Germany (right) has subsidized demand.

sources even further and faster than in the past five years. The cost of crystalline silicon photovoltaic (PV) modules has fallen by $99 \%$ since 1978 and by $80 \%$ since 2008 ; installation costs for wind power have also dropped, and solar and wind capacity has grown $^{2}$ (see 'The rise of renewables'). Prices will continue to fall, but - without more help - the decrease will not be fast enough to make a dent in the climate problem.

Some obstacles are technological; many are policy-driven ${ }^{3,4}$. Most energy regulations were set with the fossil-fuel industry in mind, and energy providers fight to preserve their existing assets rather than adapt to new conditions. More strategic coordination of energy resources, grid operation and climate policy is needed, keeping in mind trade-offs.

\section{GRID OF POWER}

We call for policymakers to modernize and open up access to power grids, and to subsidize key technologies - particularly for storage. Renewables must have the same access to the grid as fossil sources; and grids must accept and manage distributed generation and intermittent flows. Other investments must include support for research, development and demonstration of energy storage and new low-carbon energy technologies. Barriers to international trade in renewable technologies and services must be lowered.

We are in the middle of a low-carbon- energy revolution. Germany has proved an early driving force on the demand side and China has been strong on the supply side. Germany's Renewable Energy Sources Act, adopted in 2000, guaranteed 20 years of grid access and fixed prices for its solar- and wind-power producers. German electricity consumers are subsidizing the expensive early stages of the development, deployment and integration of renewables to the tune of more than $\$ 20$ billion a year. In 2014, despite the country exporting more electricity than ever to its neigh-

"With no
single 'best"
solution
available,
controlled
policy
experiments
are needed."
bours and phasing out nuclear power, carbon emissions from the German power sector were the second lowest since 1990.

Meanwhile, China's climate, energy and industrial policies have boosted the manufacturing scale of renewable technologies, expanding solar PV production more than 100-fold since 2005 (ref. 5). As a result, PVmodule prices have come down faster than anticipated. Other countries are taking note. More than half of US states are mandating an increase in the proportion of renewable power and have an incentive to expand such programmes under the Clean Power Plan.

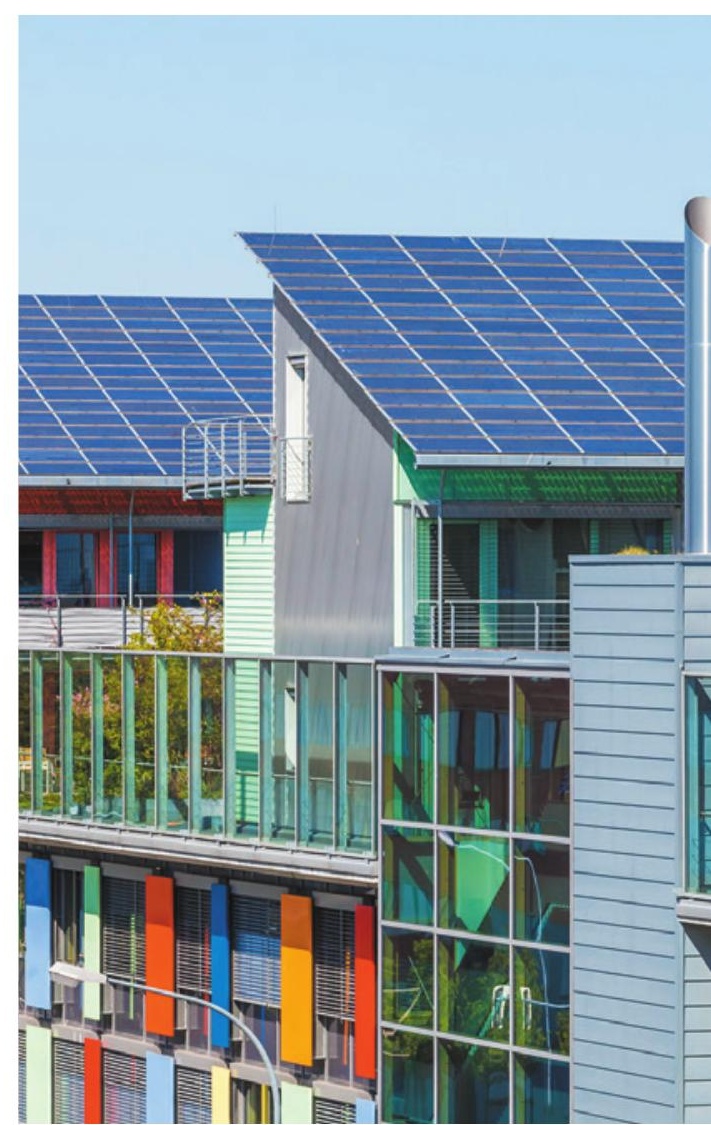

But 'business as usual' is not enough. Even Germany - where solar energy meets more than $50 \%$ of national electricity demand on a sunny Sunday afternoon (when the sun is out and demand is low) - gets more than half of its annual electricity from coal and natural gas. Further reduction of fossil fuels relative to renewables is not assured. Fossil-fuel prices are volatile, and demand for renewables stalls when coal and natural gas are cheap.

Poorly designed subsidies can be counterproductive because some low-carbon technologies perform better than others. Some forms of bioenergy may increase rather than reduce net emissions, owing to energy-intensive, fossil-fuel-based production processes and land-use changes, such as deforestation ${ }^{6}$. The reservoirs of hydropower dams may leak methane, and nuclear plants are expensive and carry large potential environmental risks. Still, the worst offenders are subsidies for conventional fossil fuels.

\section{OPEN EXPERIMENT}

The ideal solution is to vary the price of electricity by time and location, reflecting the full costs of generation and distribution - including environmental costs. But that leads to another dilemma: proper pricing at all levels is politically and analytically difficult. Compromises and alternative instruments are needed. For example, 


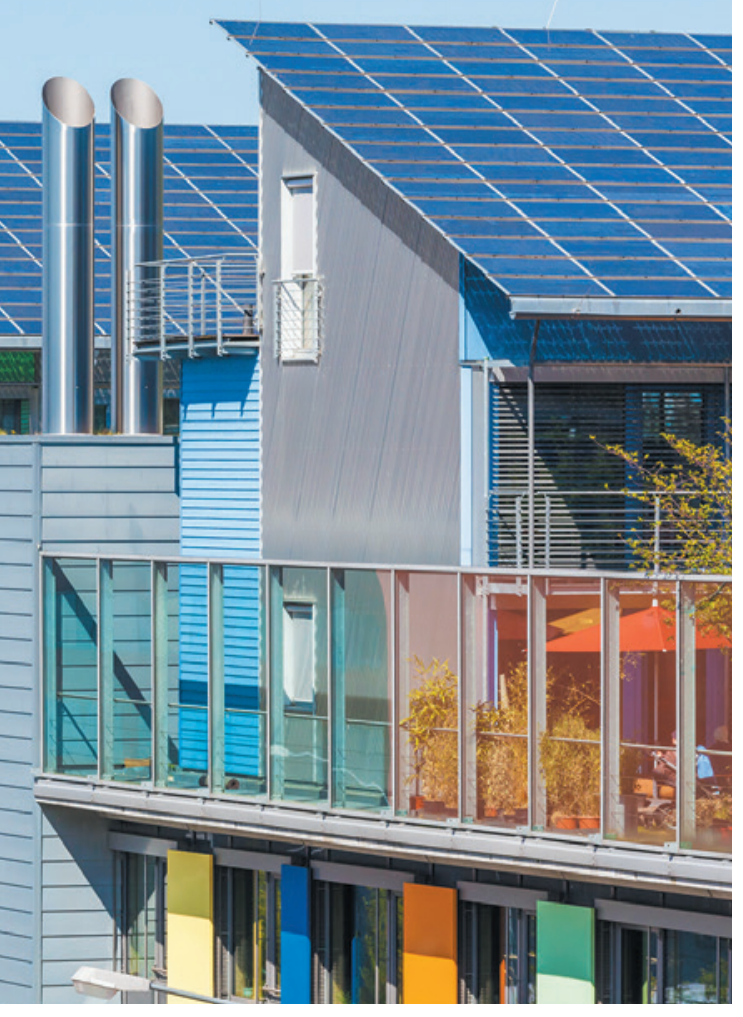

German feed-in tariffs that guarantee fixed prices for renewable-energy generation led to large increases in solar and wind installations. However, as the prevalence of renewable energies increases, the system needs - and is undergoing - reform. With no single 'best' solution available, controlled policy experiments are needed.

First, policymakers must check that interventions pass the benefit-cost test. Given how far the world remains from a sensible global climate policy, this is often a low threshold. Many direct subsidies that support renewables - especially solar energy - are beneficial, not least because they spur learning-by-doing ${ }^{7}$.

Second, any renewables policy should make a national - and eventually global carbon cap or tax more likely. If an intervention might derail such efforts, then stop. If it paves the way for stronger climate policy, try it. The Clean Power Plan, for example, encourages flexible, market-based ways of achieving emissions-reduction goals and creates a framework for trading between states a clear boon to sensible carbon pricing.

Third, governments should break up non-competitive arrangements around grid access. Funding and regulation should support the modernization of power grids to allow new renewable energy sources to be integrated. So that everyone pays their fair share towards the upkeep of the infrastructure, grid users should be charged - but

\section{THE RISE OF RENEWABLES}

Global wind- and solar-power capacities have grown by 40-50 gigwatts each year since 2008 , with consumption also rising (1). Meanwhile, prices of photovoltaic (PV) panels and solar energy have fallen steeply since 2010 (2), in part driven by climate and energy policies and more-efficient manufacturing.

1 Consumption and capacity increasing
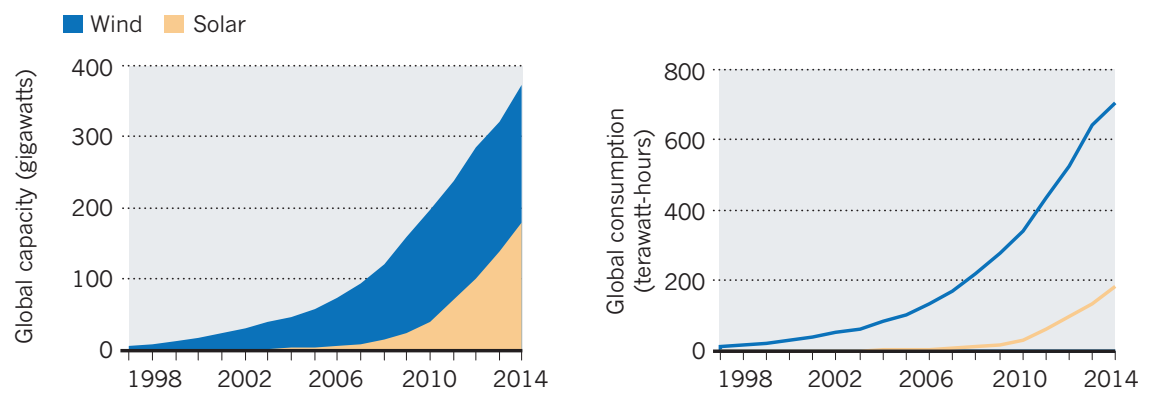

2 Costs declining rapidly
PV system, Germany Wind turbines, global
— PV panels, Germany $\square$ PV panels, China
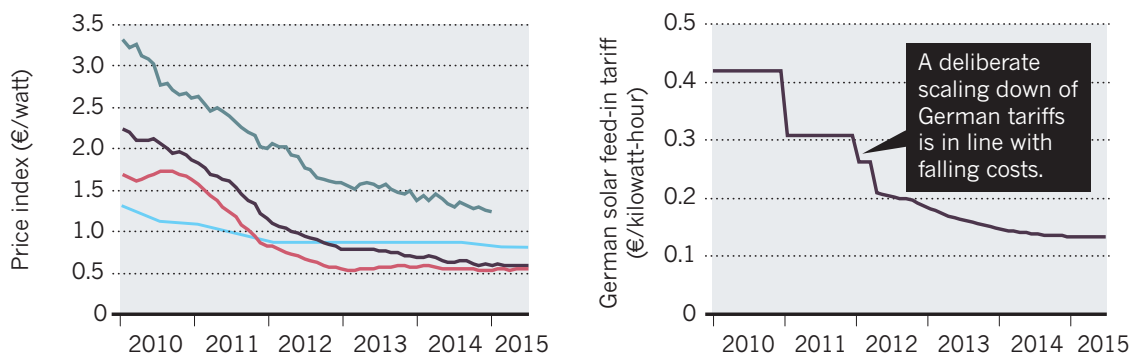

with caution. High rates might provoke some consumers to disconnect, increasing costs for the rest. Boosting supply of renewables during peak times might in turn lower peak pricing and thus (perversely) decrease overall incentives for renewables adoption ${ }^{8}$.

Fourth, the energy sector should be viewed in its entirety. For instance, increased electric-vehicle use could spread electricity demand more evenly throughout the day, flattening traditional peaks. It would also help to lower the prices of battery technologies, hastening systemic change in the transport and electricity sectors.

Ambitious renewables policies should be followed by strengthened climate policies. For example, rapid renewables deployment has reduced Germany's carbon emissions but has not brought down the EU total, because German emissions are capped under the EU's Emissions Trading System. The decrease in Germany, all else being equal, is compensated by emissions increases elsewhere under the cap. All else must not be equal. The cap ought to be tightened.

These are the sorts of pieces that need to come together to deepen solar and wind penetration levels and achieve the 'holy grail' of climate policy: an effective carbon price.

Gernot Wagner is lead senior economist at the Environmental Defense Fund in Boston, Massachusetts, USA, and adjunct associate professor of international and public affairs Tomas Kåberger is professor of industrial energy policy at Chalmers University of Technology, Gothenburg, Sweden. Susanna Olai is an environmental economist at the University of Gothenburg, Sweden. Michael Oppenheimer is professor of geosciences and international affairs in the Woodrow Wilson School and the Department of Geosciences, Princeton University, New Jersey, USA. Katherine Rittenhouse is an economic analyst at the Environmental Defense Fund in Boston, Massachusetts, USA. Thomas Sterner is professor of environmental economics at the University of Gothenburg, Sweden, and senior contributing economist at the Environmental Defense Fund in New York, USA.

e-mail:gernot@gwagner.com

1. Wagner, G. \& Weitzman, M. L. Climate Shock The Economic Consequences of a Hotter Planet (Princeton Univ. Press, 2015).

2. Trancik, J. E. Nature 507, 300-302 (2014).

3. Prentiss, M. Energy Revolution: The Physics and the Promise of Efficient Technology (Harvard Univ. Press, 2015).

4. Energy Initiative, Massachusetts Institute of Technology. The Future of Solar Energy (MIT, 2015).

5. Mathews, J. A. \& Tan, H. Nature 513, 166-168 (2014).

6. Searchinger, T. D. et al. Science $\mathbf{3 2 6}, 527-528$ (2009).

7. van Benthem, A., Gillingham, K. \& Sweeney, J. Energy J. 29, 131-151 (2008).

8. Darghouth, N. R., Wiser, R., Barbose, G. \& Mills, A. Net Metering and Market Feedback Loops (Lawrence Berkeley National Laboratory, 2015). at Columbia University, New York, USA. 